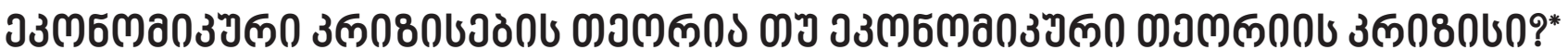

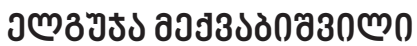

https://doi.org/10.35945/gb.2018.06.002

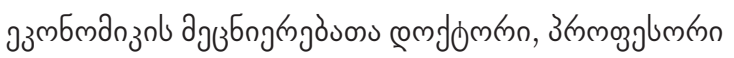

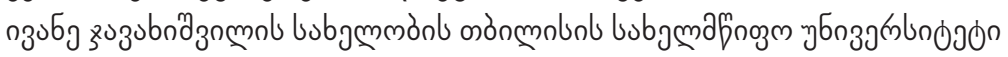

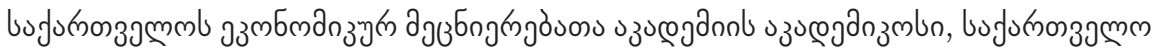

elguja.mekvabishvili@tsu.ge

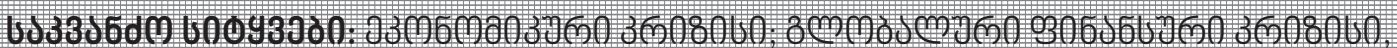

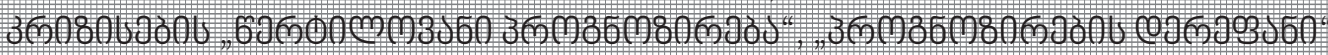

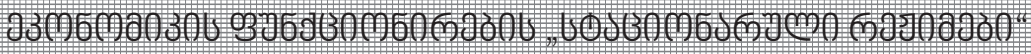

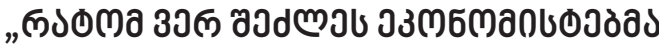

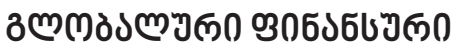

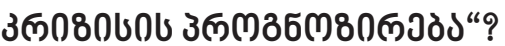

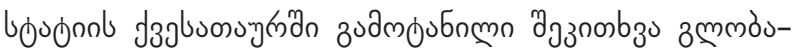

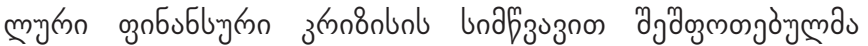

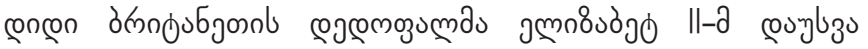

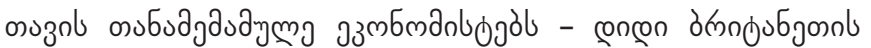

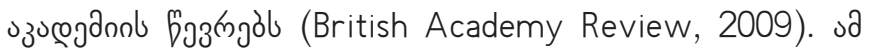

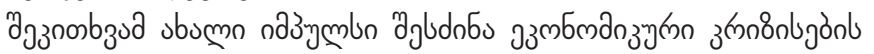

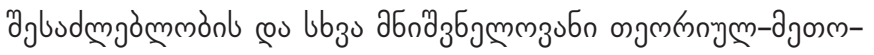

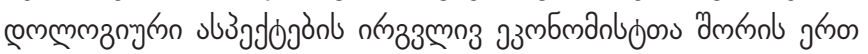

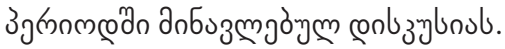

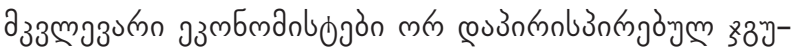

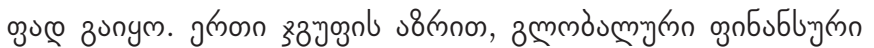
z

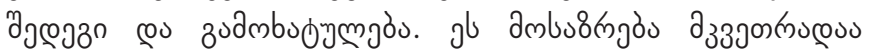

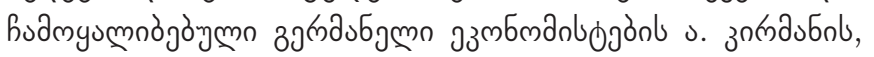

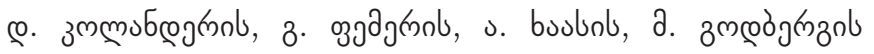

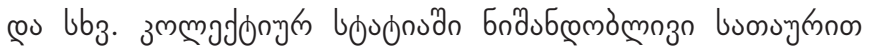

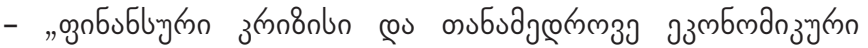

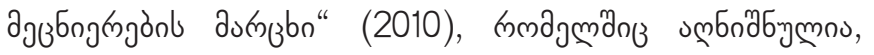

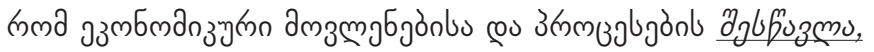

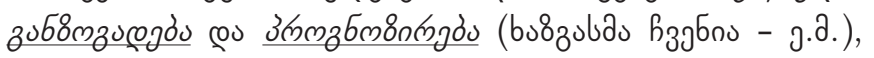

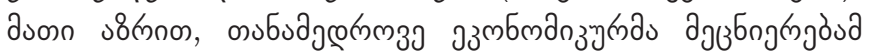

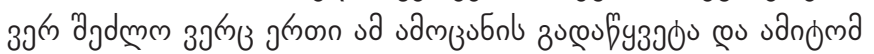

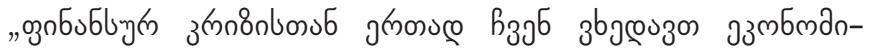

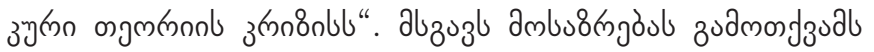

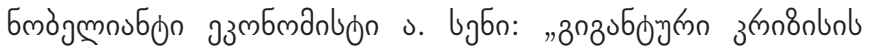

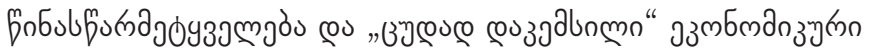

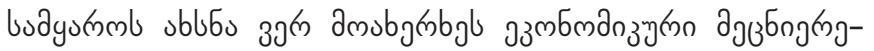

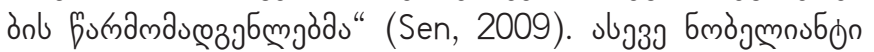

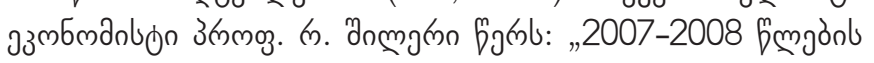

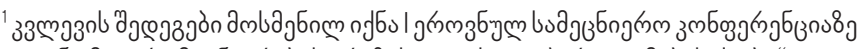

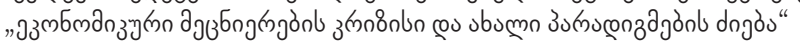

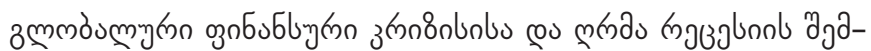

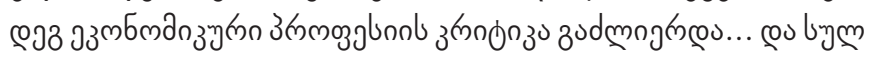

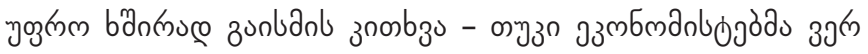

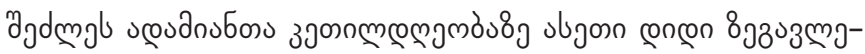

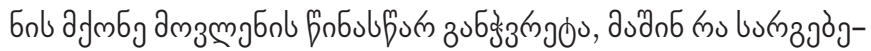
mno duonzub?" (Shiller, 2015). Inmgrnn naubur coubdgbl,

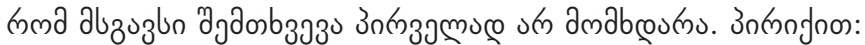

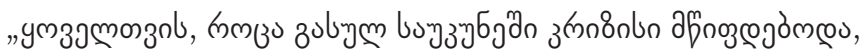

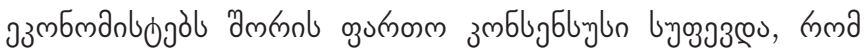

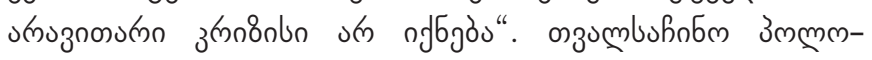

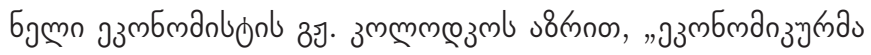

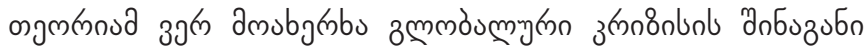

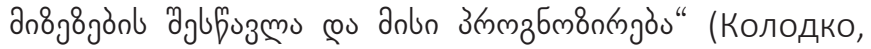

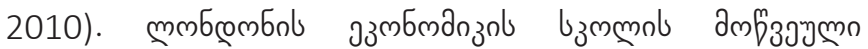

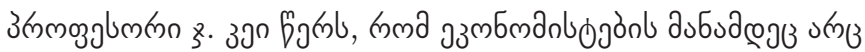

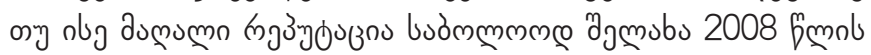

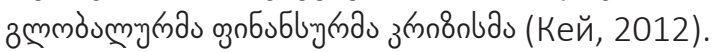

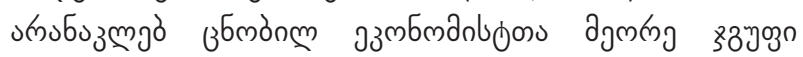

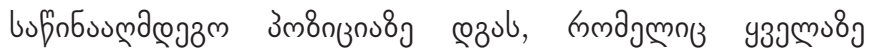

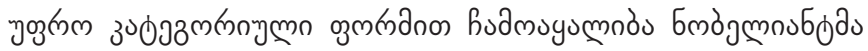

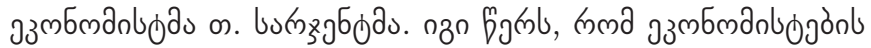

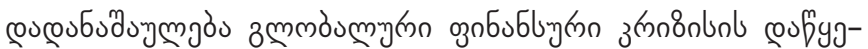

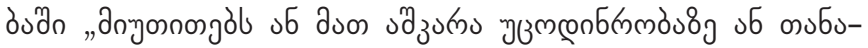

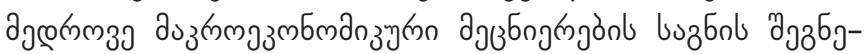

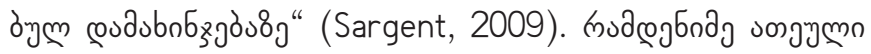

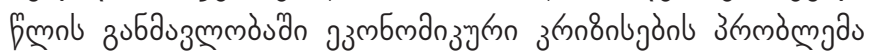

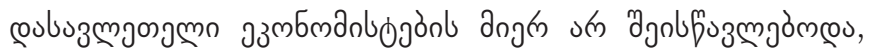

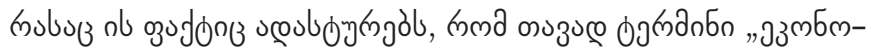

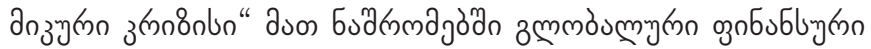

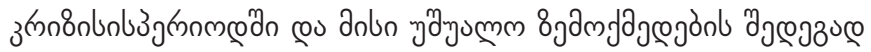
zoh5 cos.

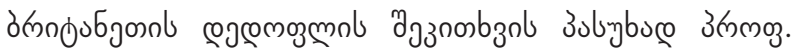

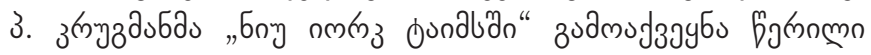

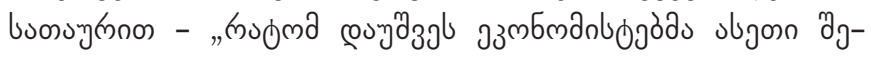

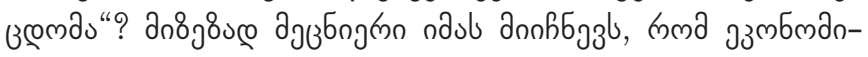

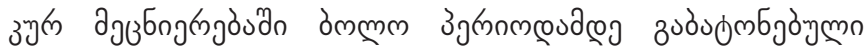




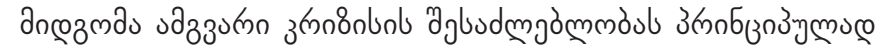

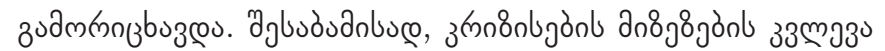

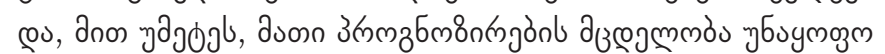

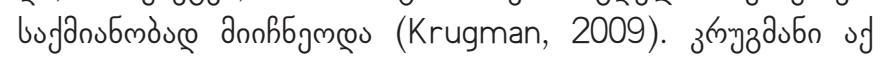

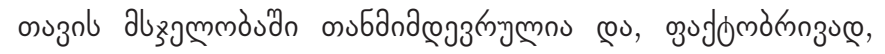

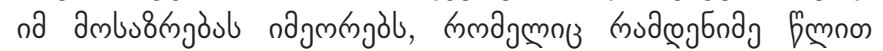

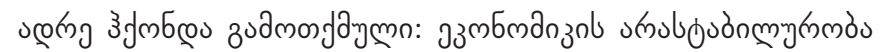

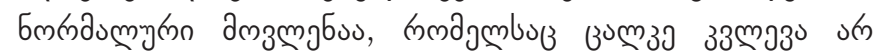

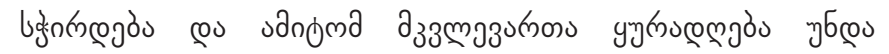

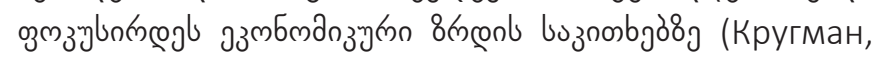
2002).

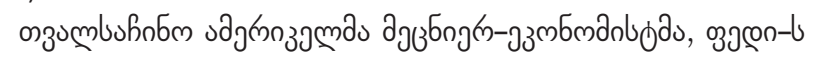

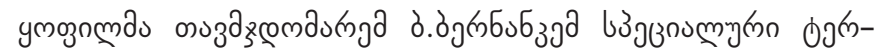

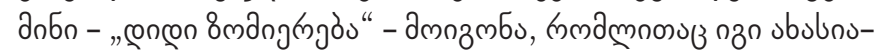

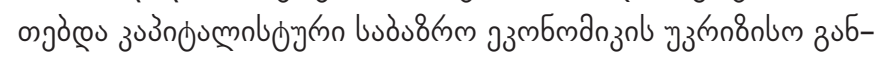

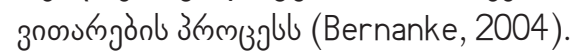

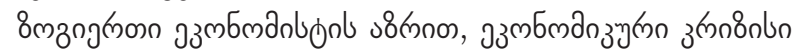

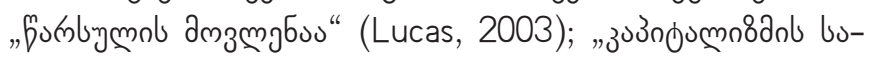

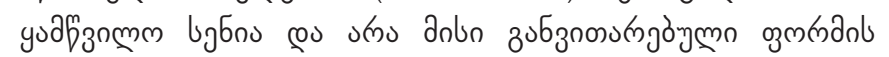

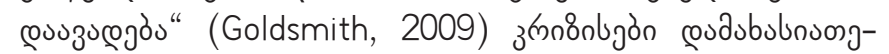

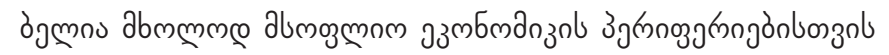
(Rajan, 2010).

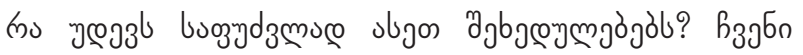

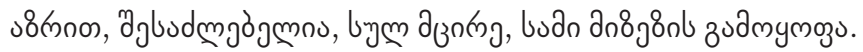

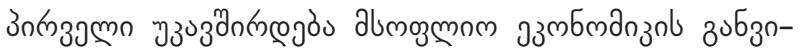

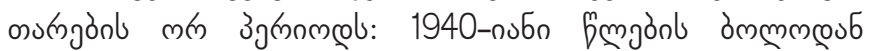

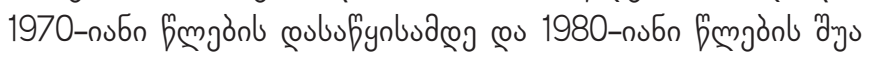

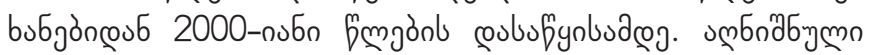

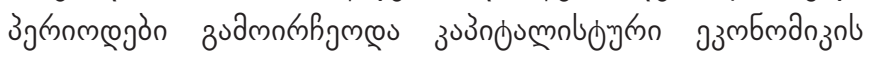

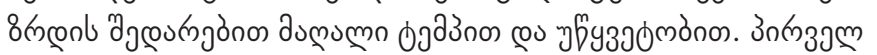

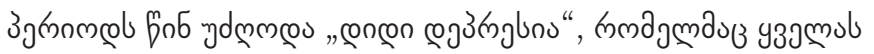

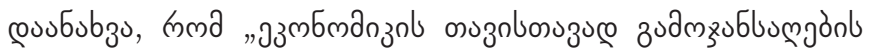
ammmen

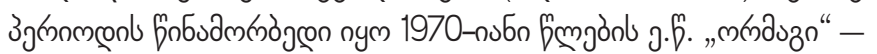

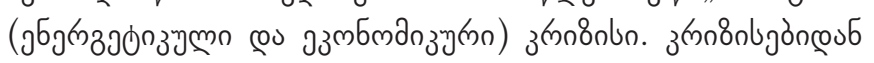

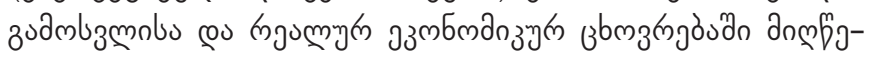

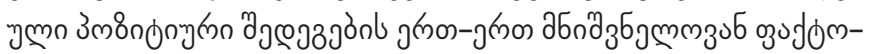

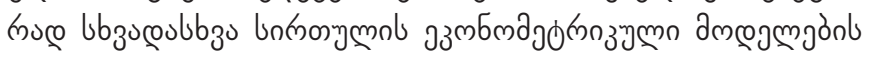

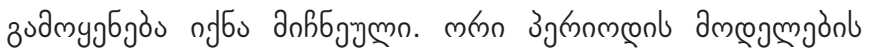

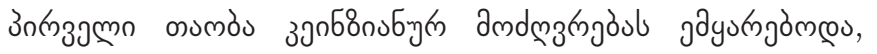

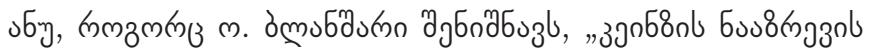

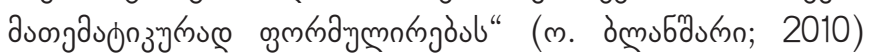

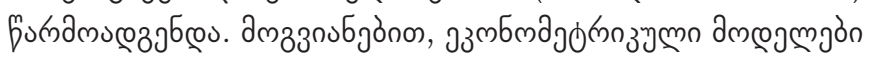

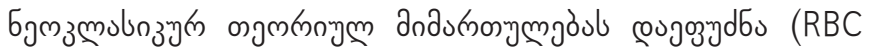

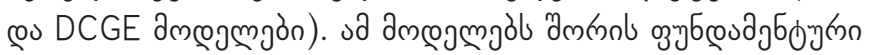

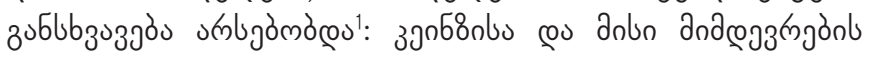

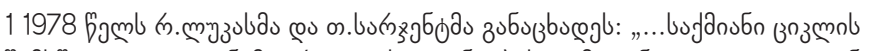

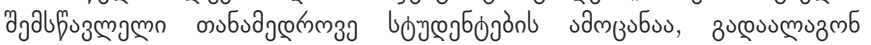

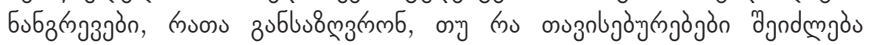

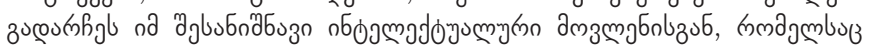

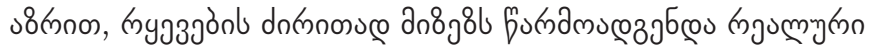

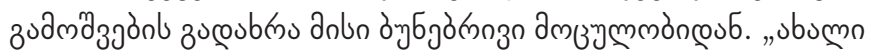

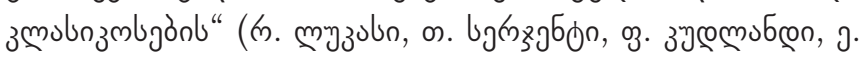

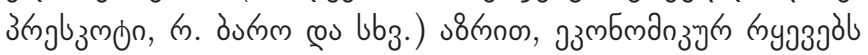

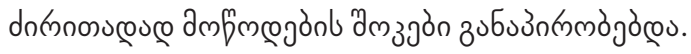

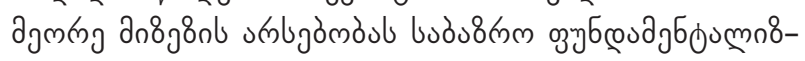

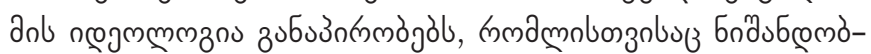

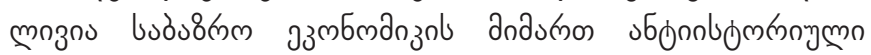

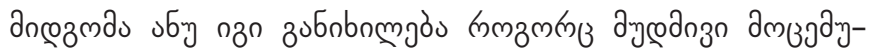

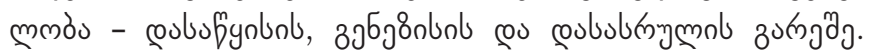

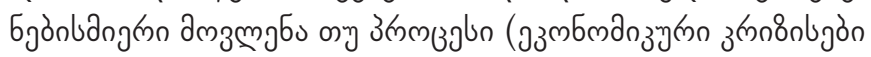

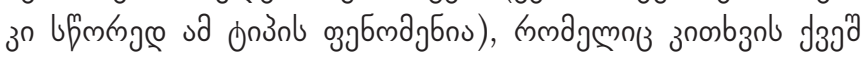

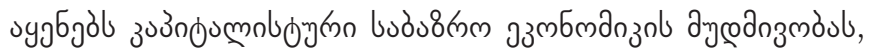

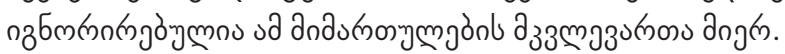

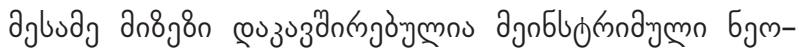

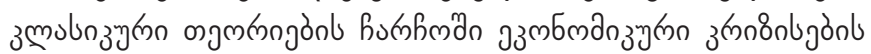

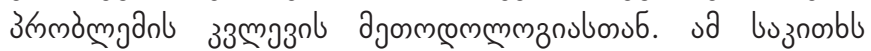

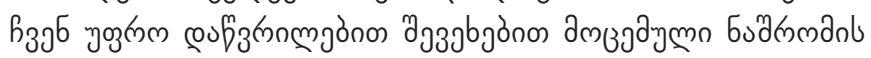

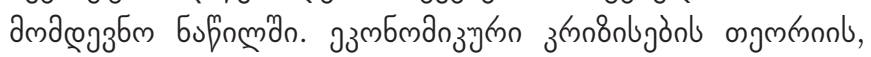

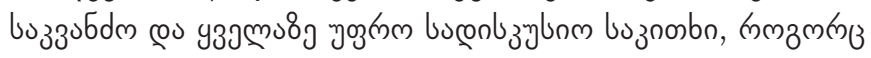

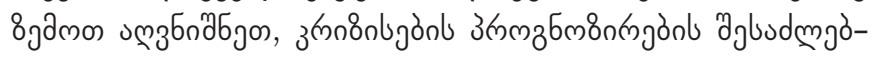

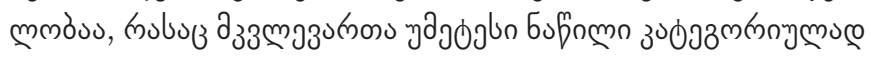

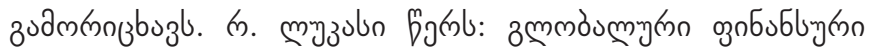

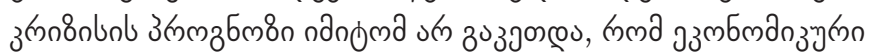

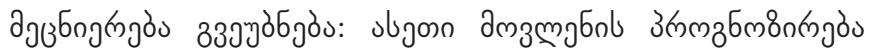

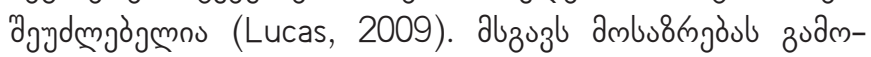

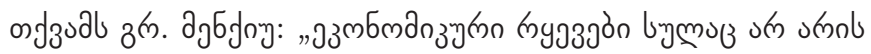

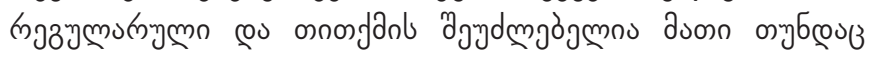

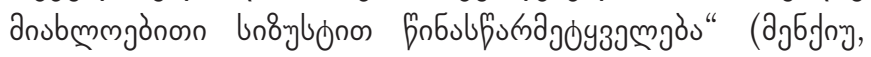

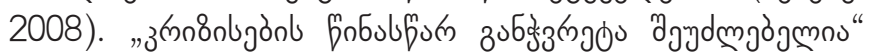

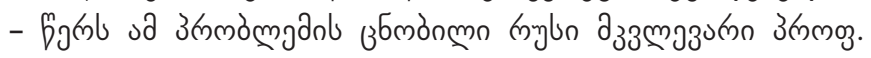
п.пјзмзэзо (Яковец, 2004).

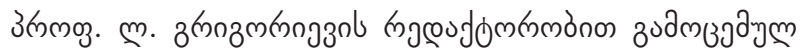

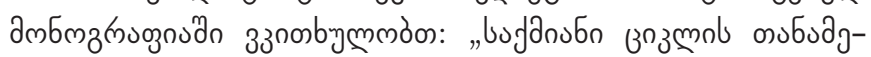

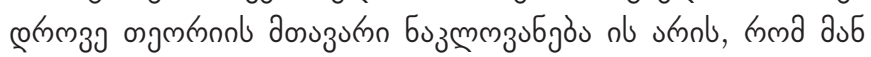

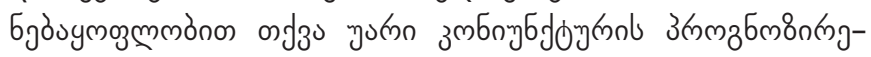

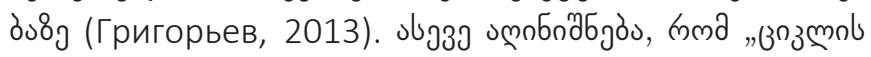

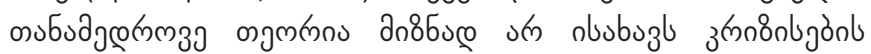

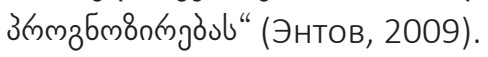

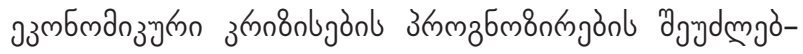

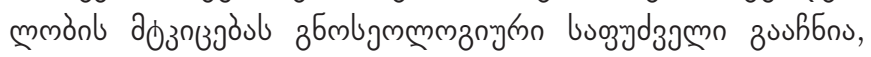

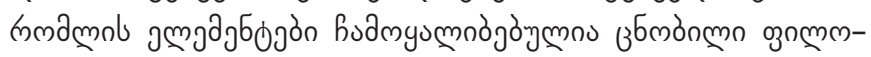

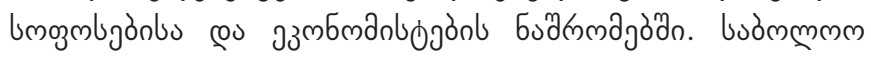

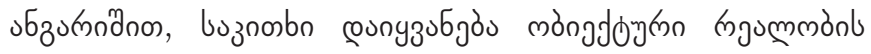

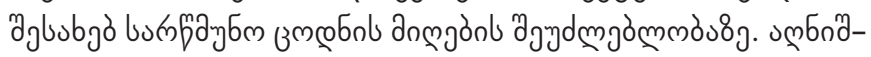

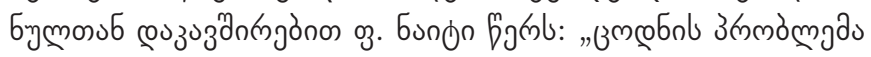

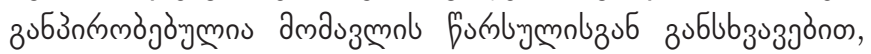

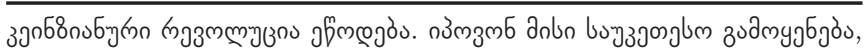

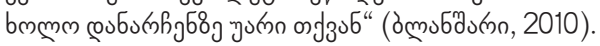




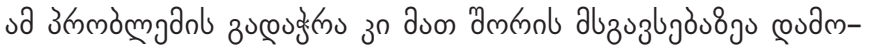

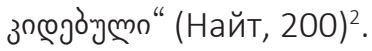

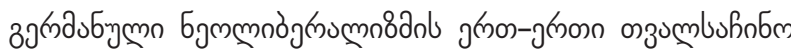
fumamà

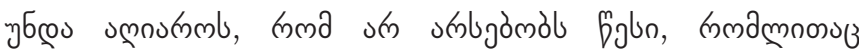

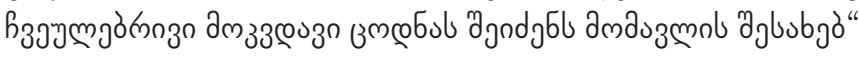
(Мизес, 2007.

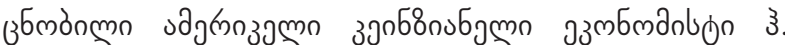

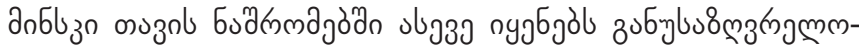

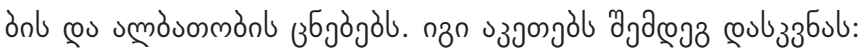

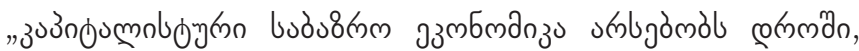

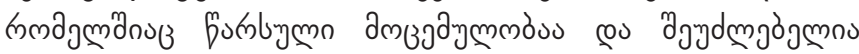

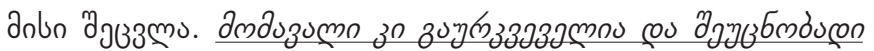

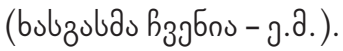

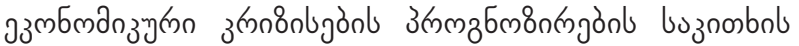

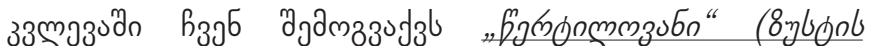

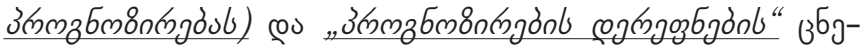

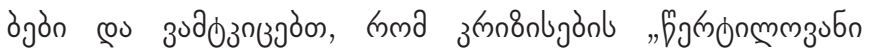

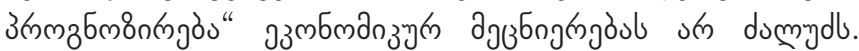

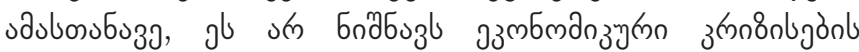

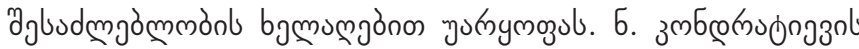

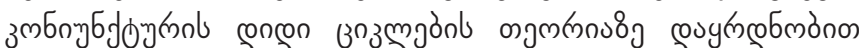

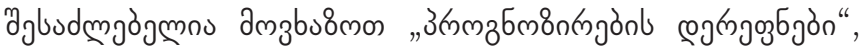

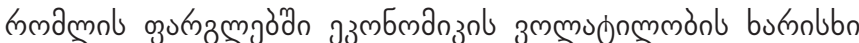

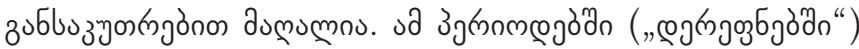

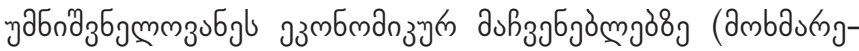

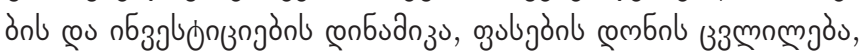

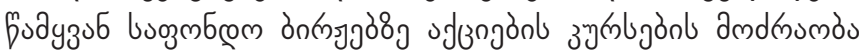

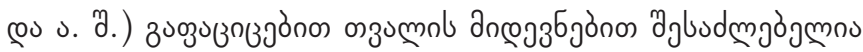

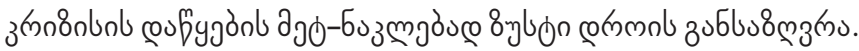

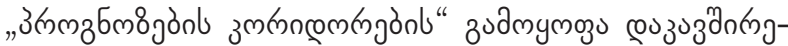

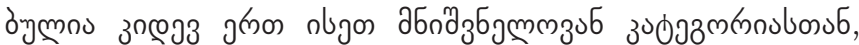

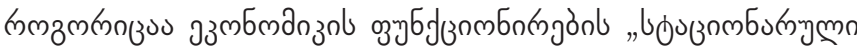

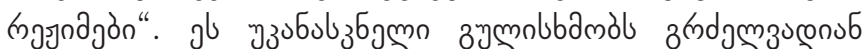

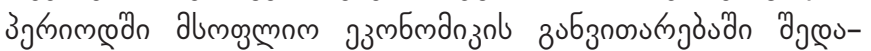

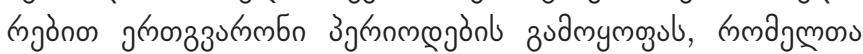

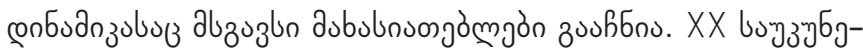

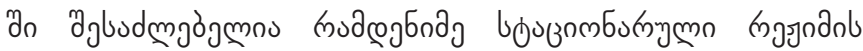
зงдmymoुs:

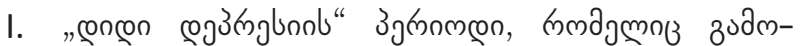

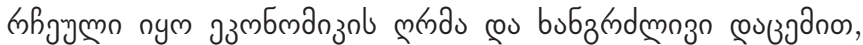

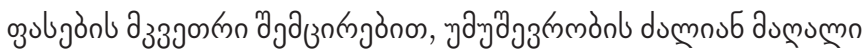

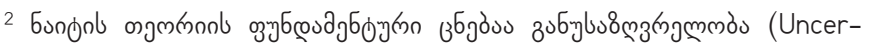

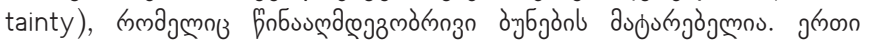

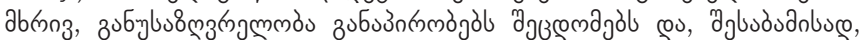

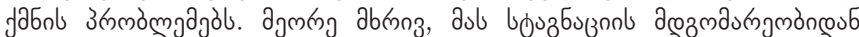

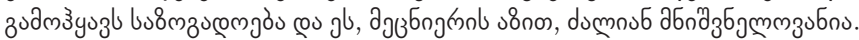

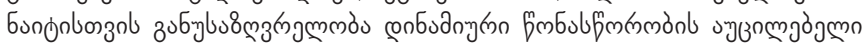

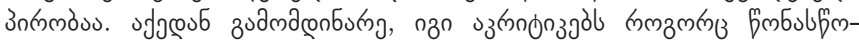

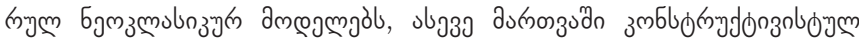
дnœ्वmajall.
}

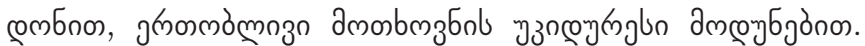

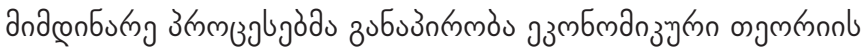

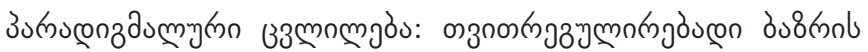

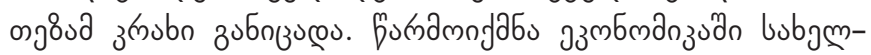

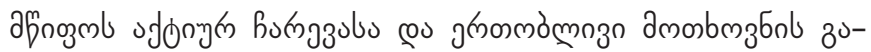

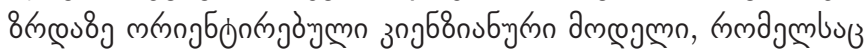
œujojgd

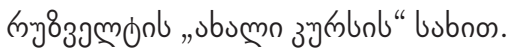

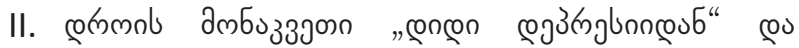

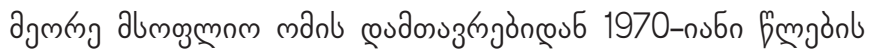

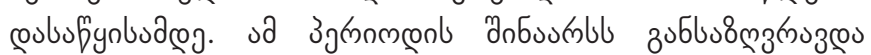

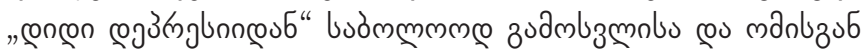

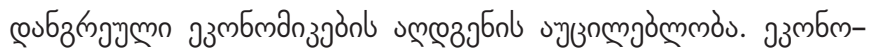

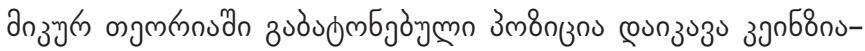

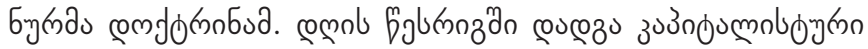

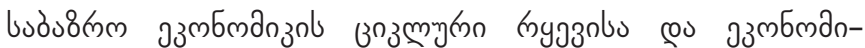

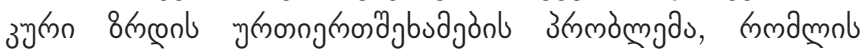

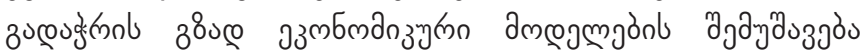

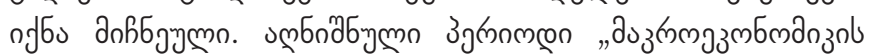

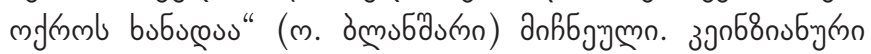

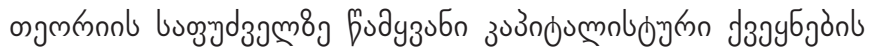

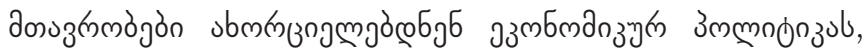

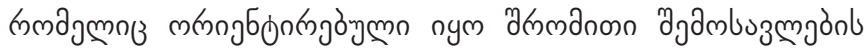
зuбचf

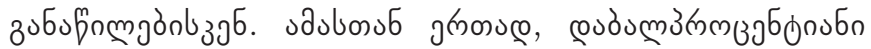
з з

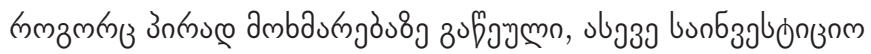

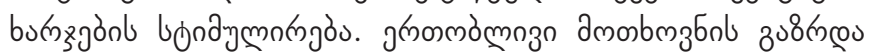

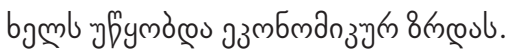

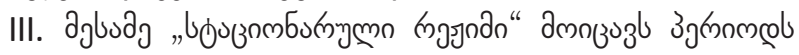

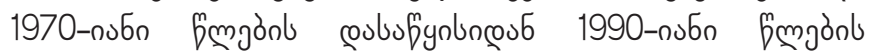

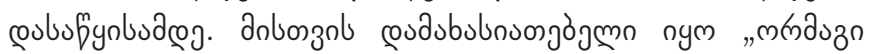

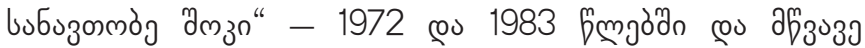

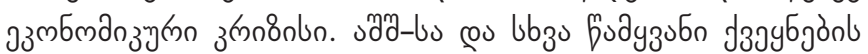

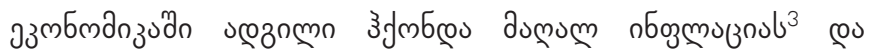

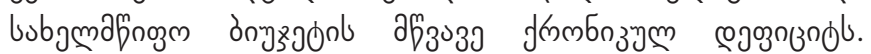

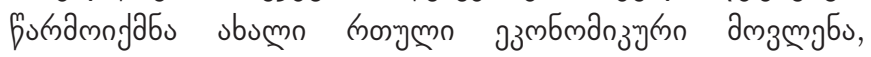

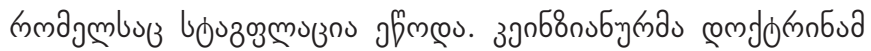
z

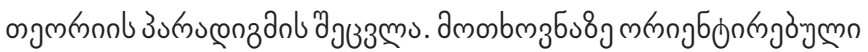

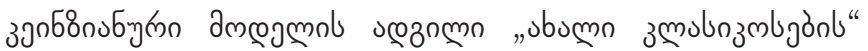

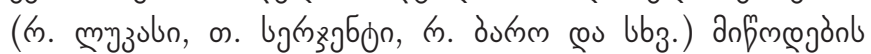

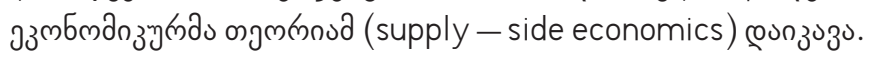

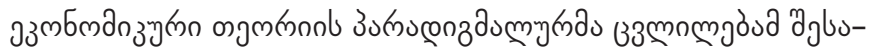

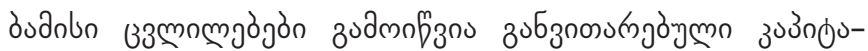

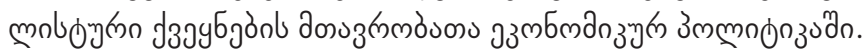

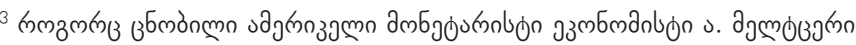

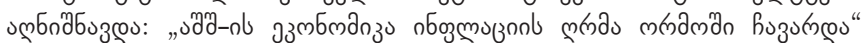
(Meltzer, 2005).
} 


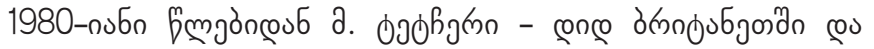

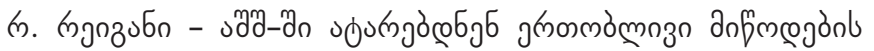

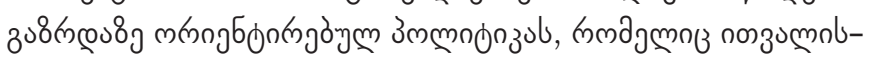

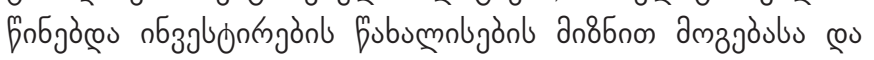

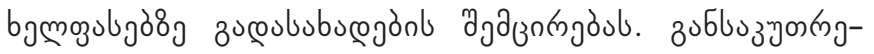

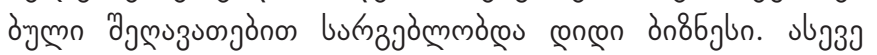

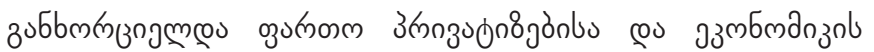

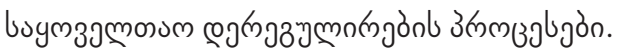

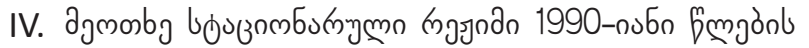

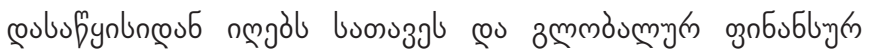

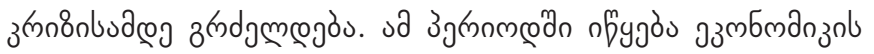

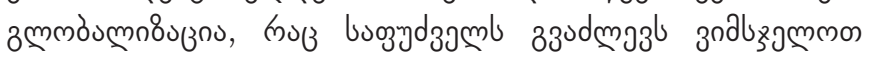

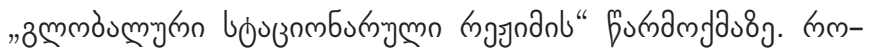

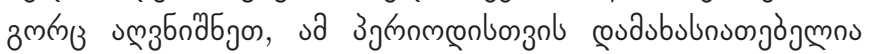

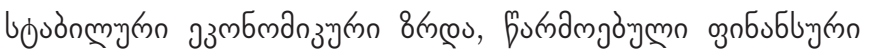
nбbj

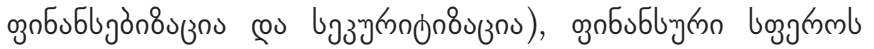

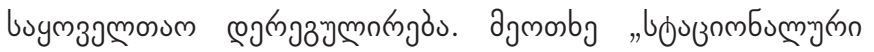

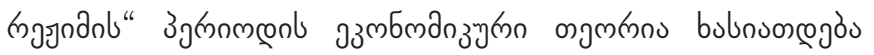

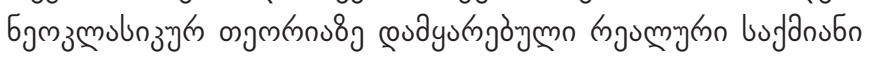

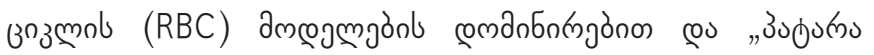

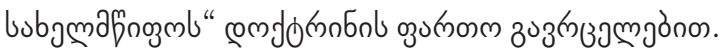

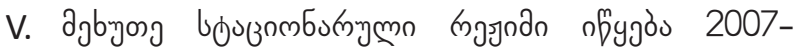

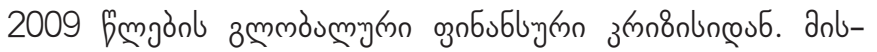

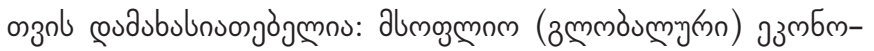

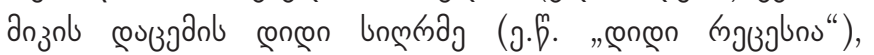

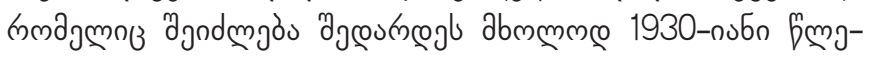

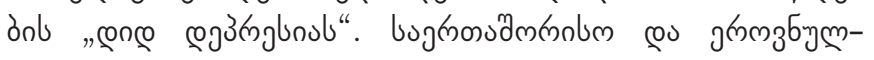

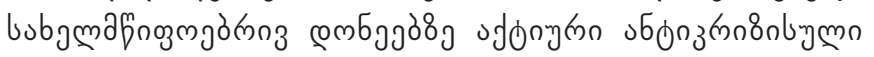

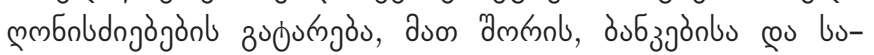

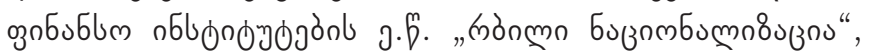

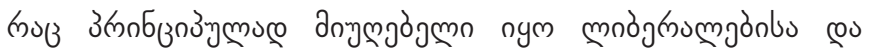

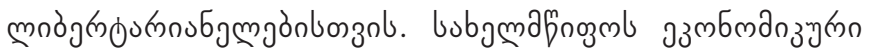

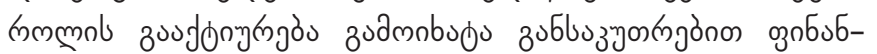

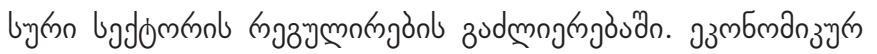

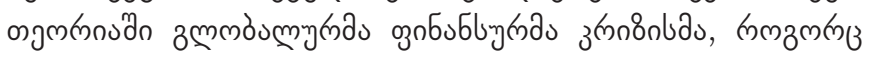

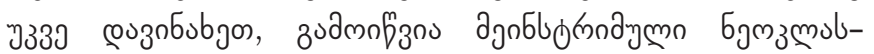

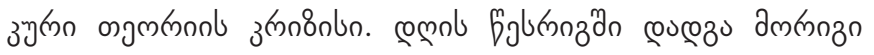

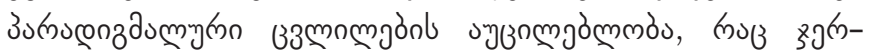

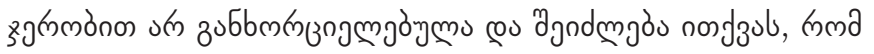

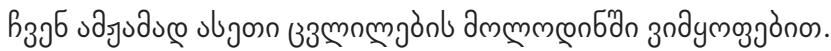

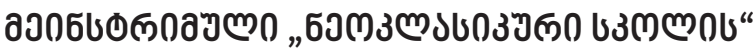

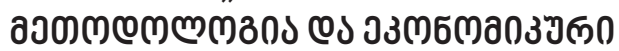

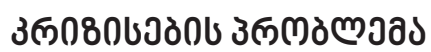

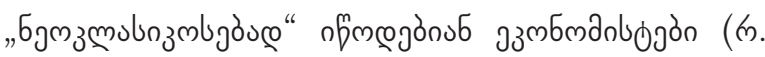

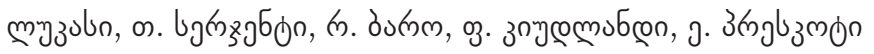

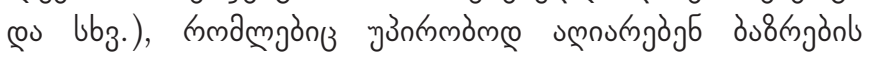

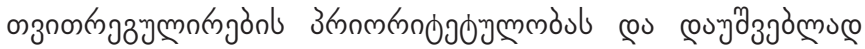

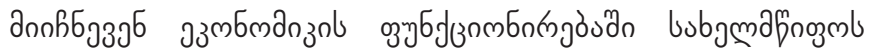

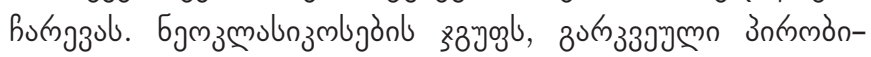

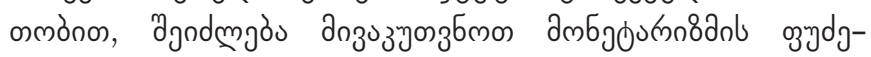

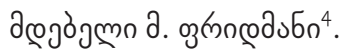

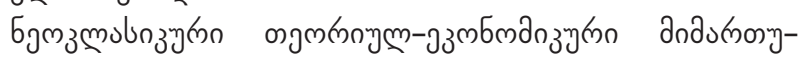

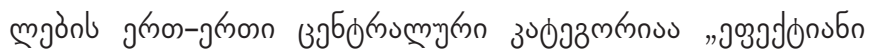

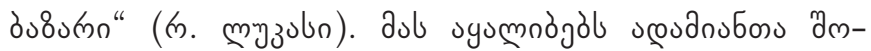

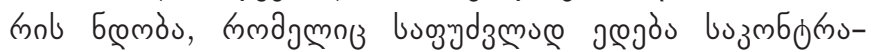

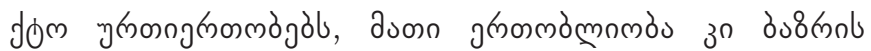

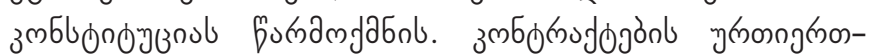

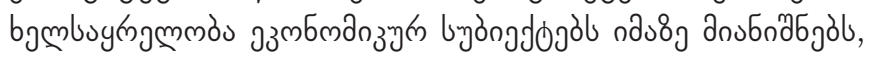

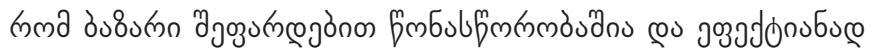

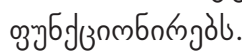

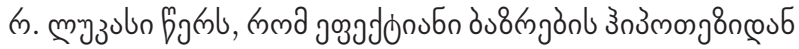

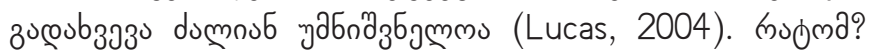

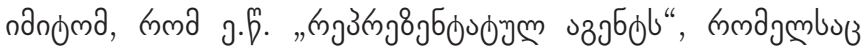

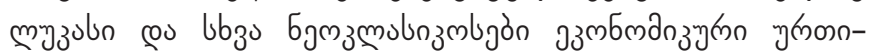

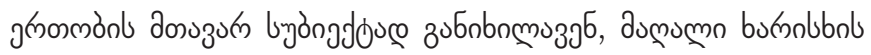

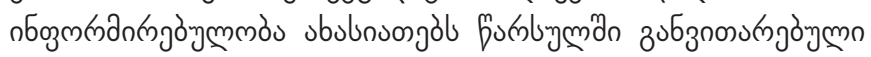

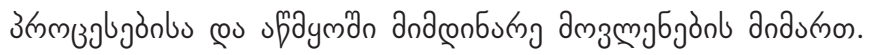
uмб

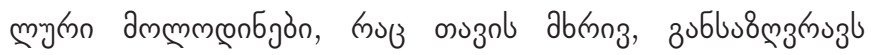

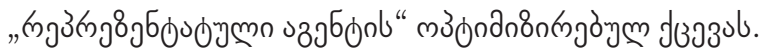

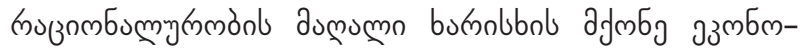

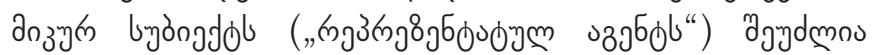
ambummenб

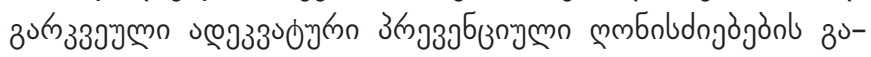

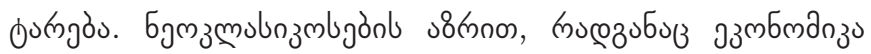

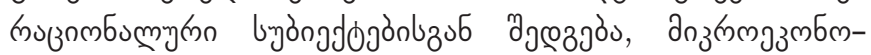

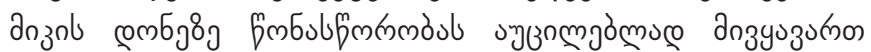

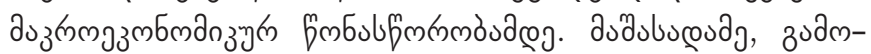

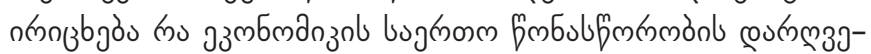

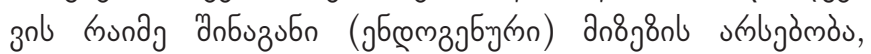

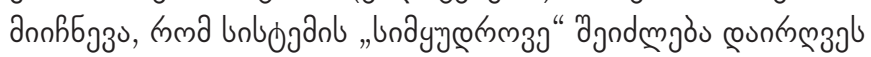
abmmme zumg (

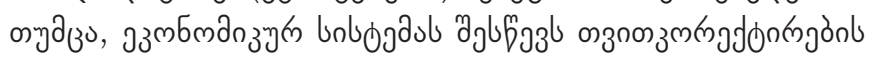

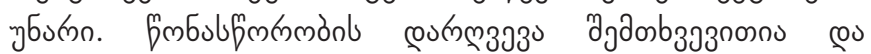

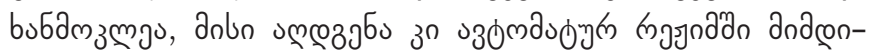

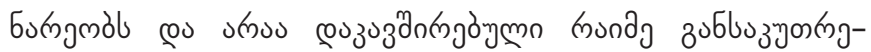

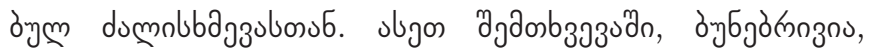

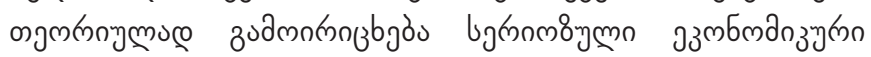

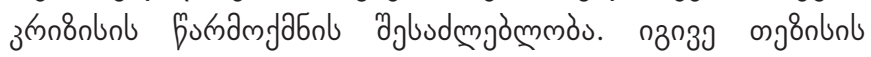

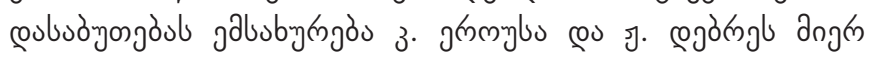

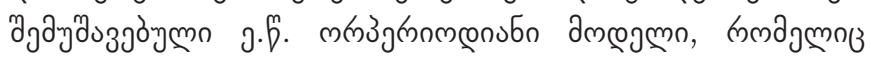

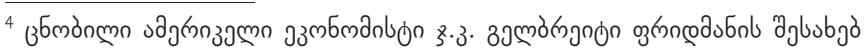

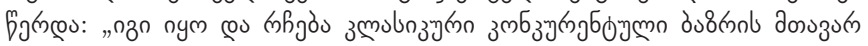

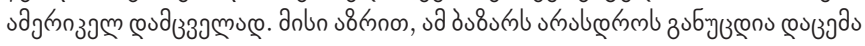

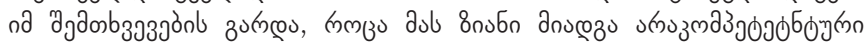

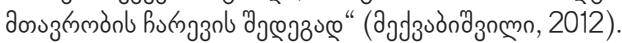




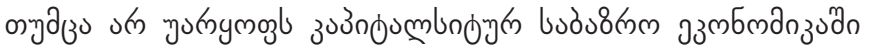

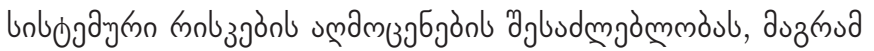

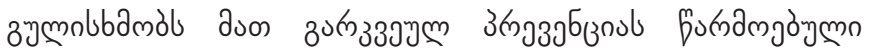

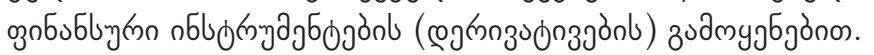

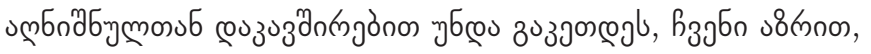

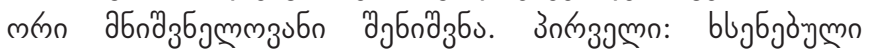

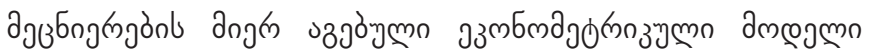

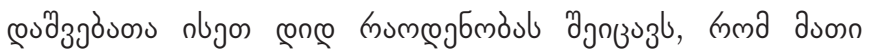
उ

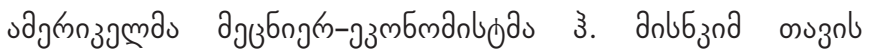

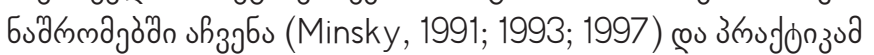

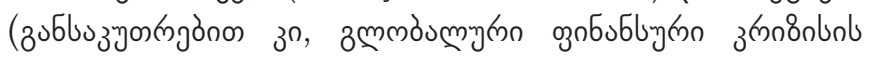

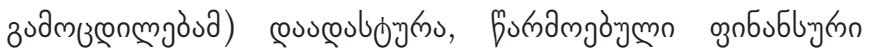

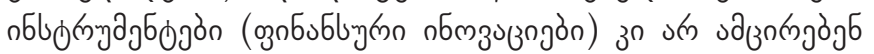

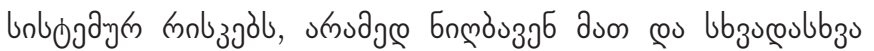

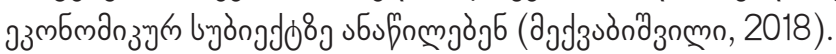

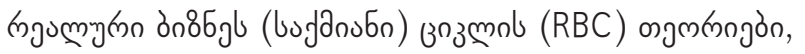

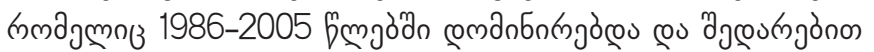

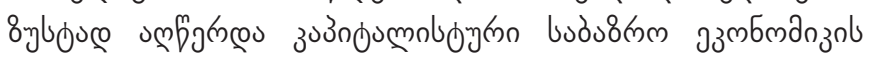

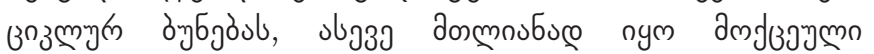

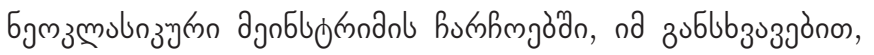

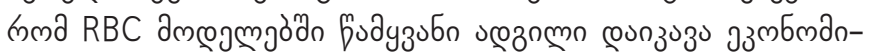

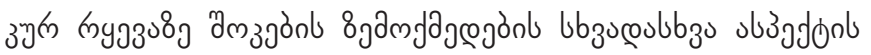
з3m93 (Kydland\&Prescott, 1982; King et al., 1988; Romer, 1999; Resolo, 2005; McCandless, 2008); Энтов,

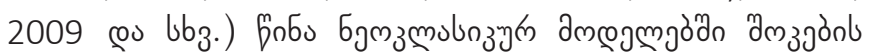

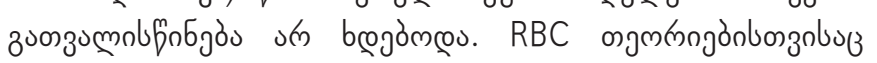

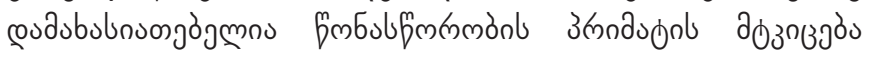

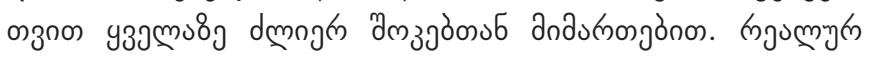

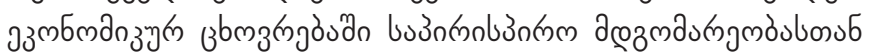

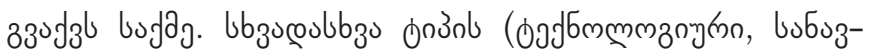

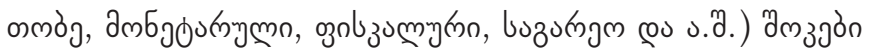

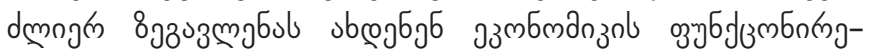

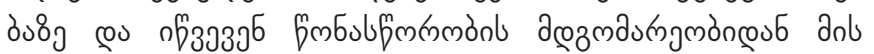

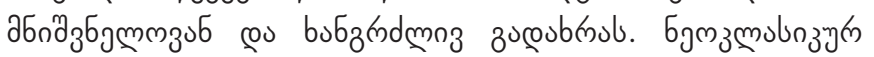

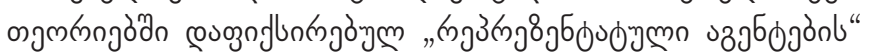

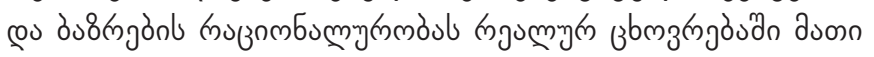

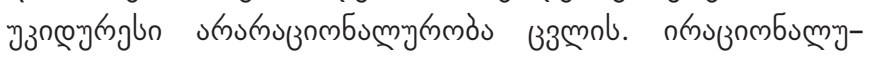

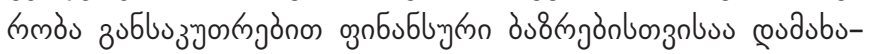

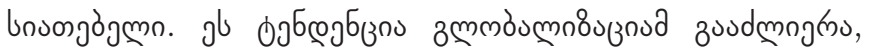
nuaus oubua gon

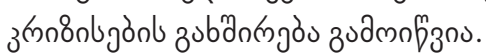

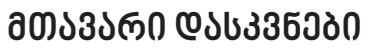

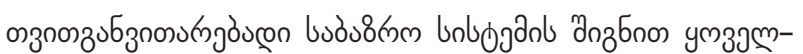

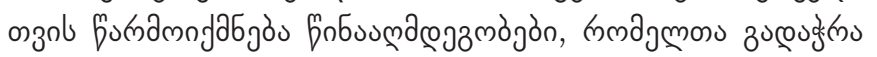

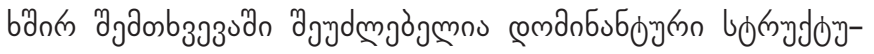

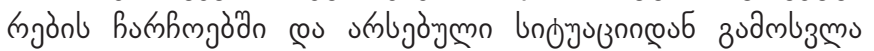

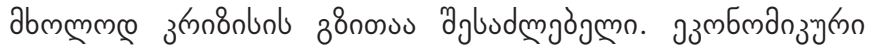

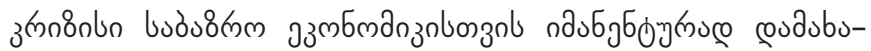

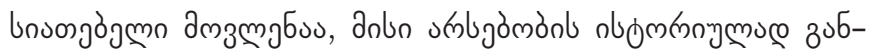

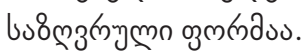

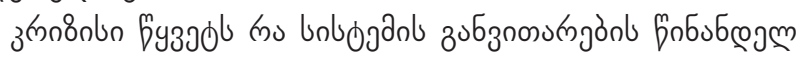

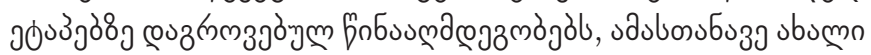

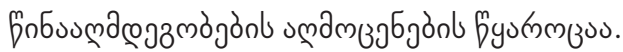

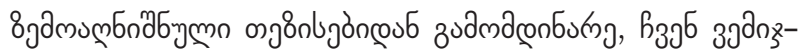

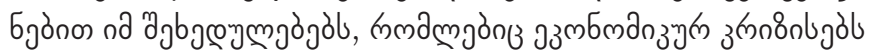

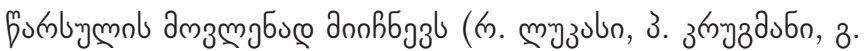

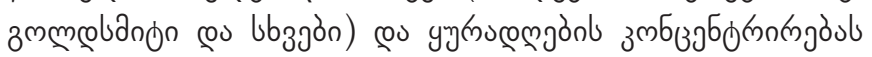

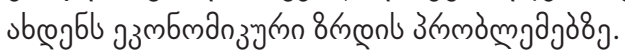

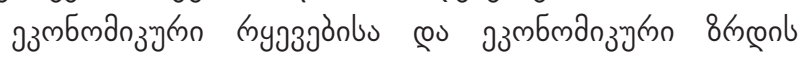

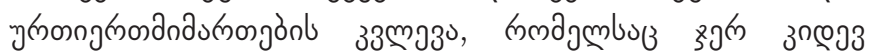

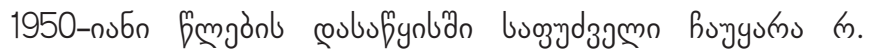

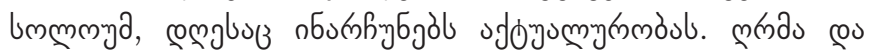

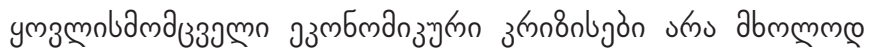

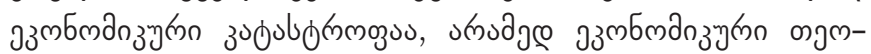

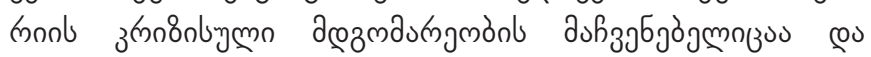

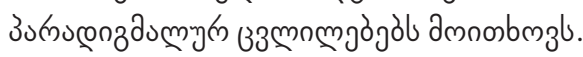

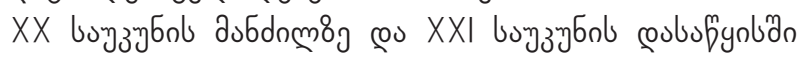

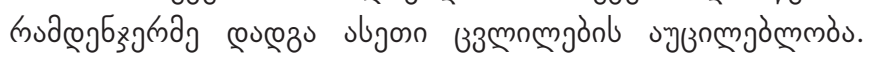

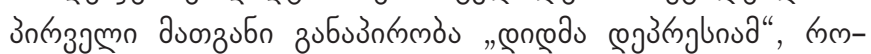

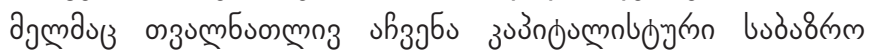

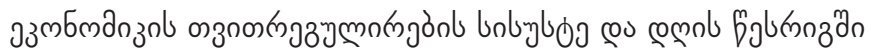

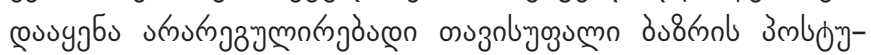

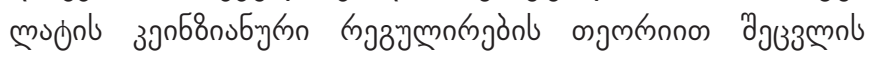

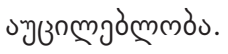

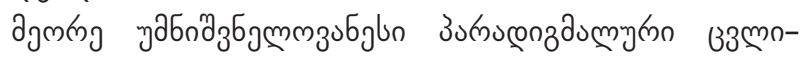

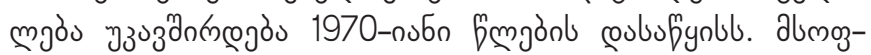

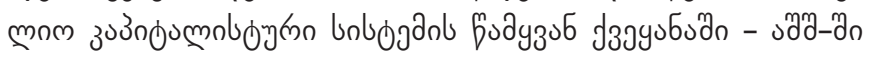

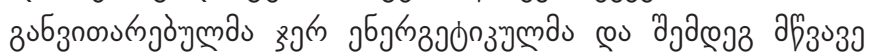

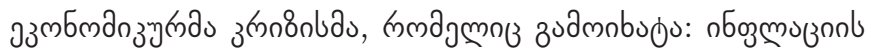
zudmngkु

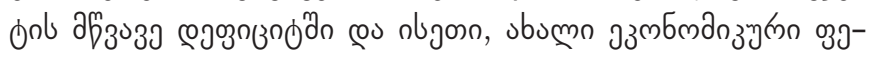

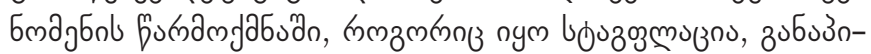

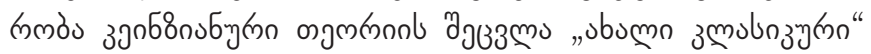

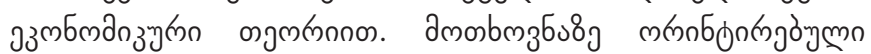

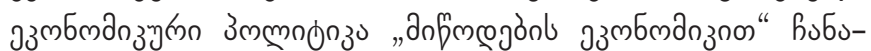

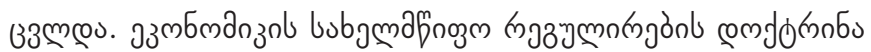

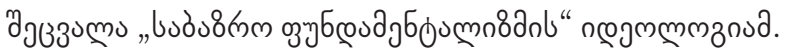

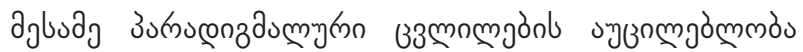

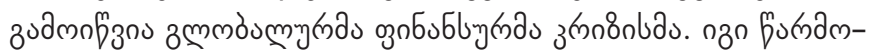

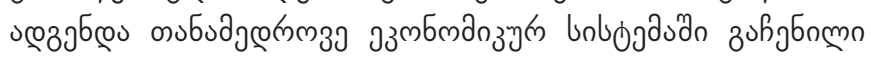

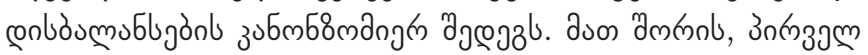

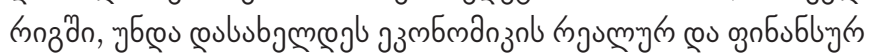

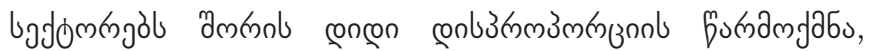

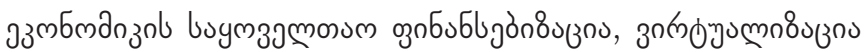

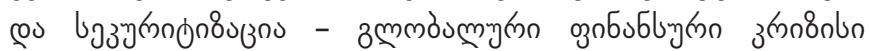




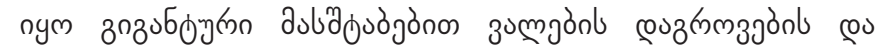

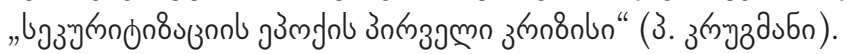

z

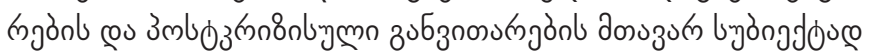

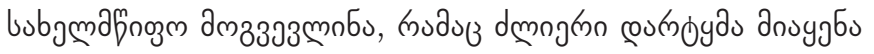

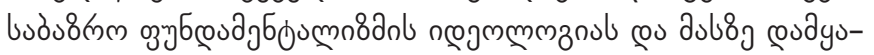

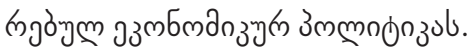

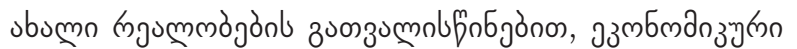

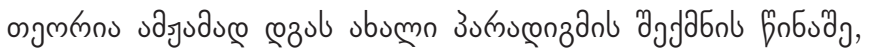

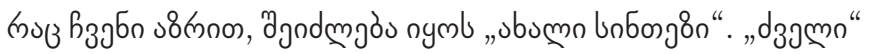

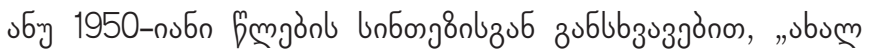

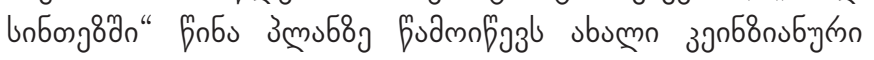

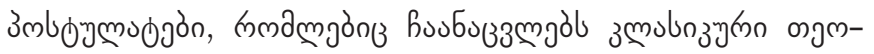

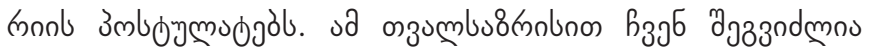

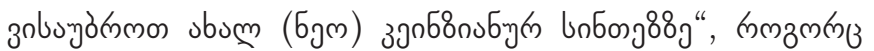

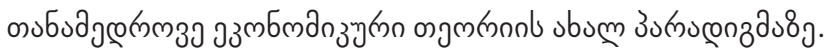

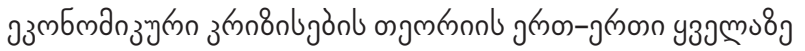

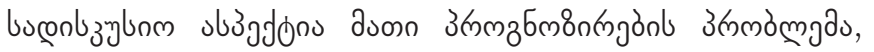

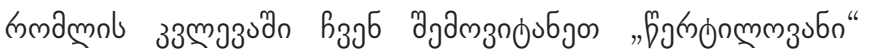

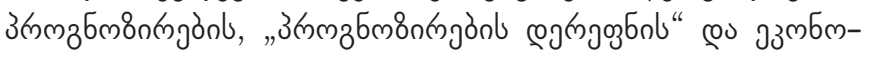

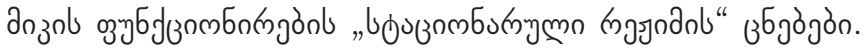

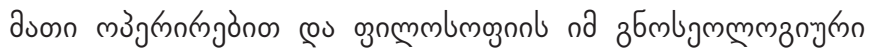

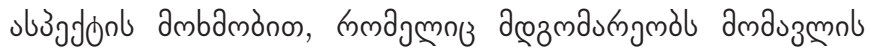

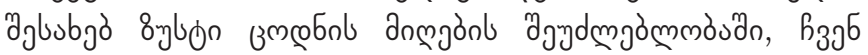

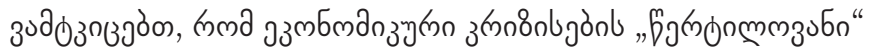

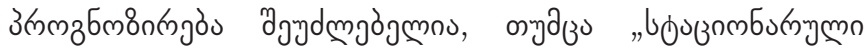

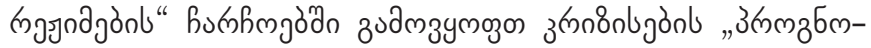

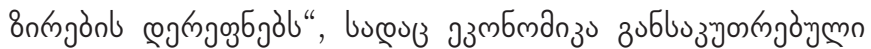

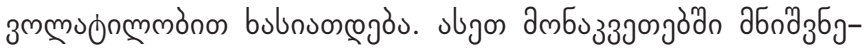

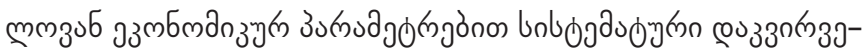

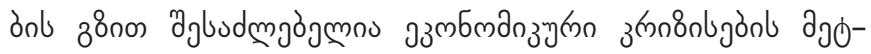

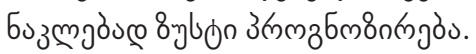

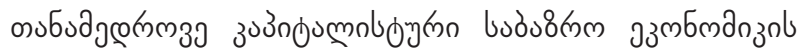

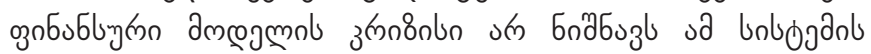

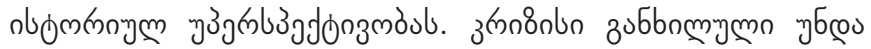

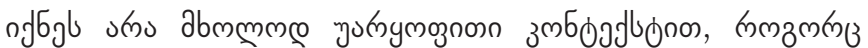

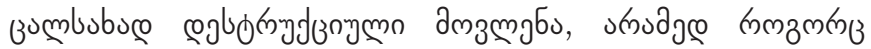

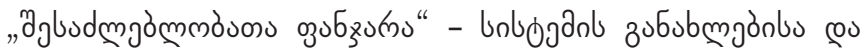

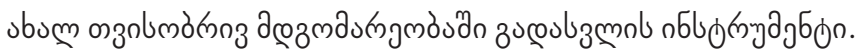

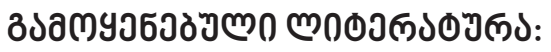

1. The Global Financial Crisis - Why Did't Anybody Notice? (2009) // British Academy Review.

2. Кирман А., Коландер Д., Феммер Г., Хаас А., Годберг Н и др. (2010). Финансовый кризис и провалы современной экономической науки // Вопросы экономики, №6.

3. Sen A. (2009). Capitalism Beyond the Crisis // New Your Review of Books/ Vol. 56, N5.

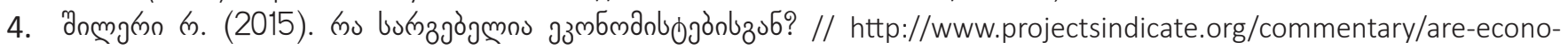
mists-good-byrobert-j-shiller-2015.01

5. Колодко Гж. (2010). Неолиберализм и мировой экономический кризис // Вопросы экономики, №3.

6. Кей Дж. (2012). Карта - не территория: о состоянии экономической науки // Вопросы экономики, №5ю

7. Sargent Th. (2010). Interview with Thomas Sargent // http://www.minneapolisfed.org/publications_papers/pub_display. cfm?id=4526

8. Krugman P. (2009).How Did Economics Get So Wrong? //The New York Times, Sept., N2.

9. Кругман П. (2009).Возвращение Великой Депресии. Мировой кризис глазами 1. нобелевского лауреата.

10. Rajan R. (2010). Has Financial Development Made the World Risker // NBER Wor5king Paper. N1172.

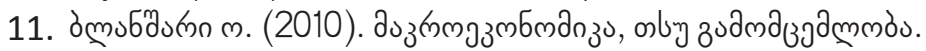

12. Lucas R. (2009). In Defense of Dismal Science//The Economist, , Aug., 6.

2. http://www.economistcom//noode1416.

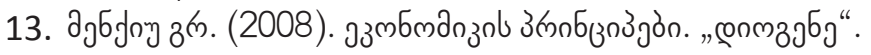

14. Яковец Ю. (2004). Экономические криэисы: неизвежная реальность / Экономические стратегии, №1.

15. Мировая экономика в начале XXI века. (2013).Под ред. Л. Григорьева. /M.,Direct Media.

16. Энтов Р. (2009). Некоторые проблемы исследования деловых циклов. М.: Проспект.

17. Наит Ф.(2003). Риск, неопределённость, прибыль. М.: «Дело».

18. Мизес Л.Ф. (2000). Человеческая деятельность. Трактат по экономической теории. М.: Экономика.

19. Kydland, F. and E. Prescott (1982), "Time to build and aggregate fluctuations", Econometrica, 50, 1345-1371.

20. MeltzerA. (2005). Originsofthe Great Inflation//Federal Reserve Bank of St. Louis Review, , vol. 87.

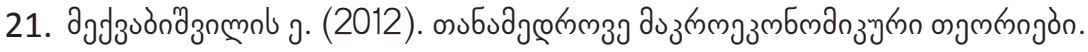


22. Minsky H. (1991).Financial Crisis: Systemic or Idiosyncratic. Jerome Levy EconomicInstitute. Bard College, Working Paper, N51, April.

23. Minsky H.(1993).Finance and Stability. The Limit of Capitalism. Jerome Levy

3. Economic Institute. Bard College Working Paper, N93.

24. Minsky H. (1994). The Financial instability Hypothesis: Capitalist Processes and Economy. University of Michigan.

25. King R., Plosser C., Rebelo S. (1988). Production, Growth and Bisness Cycles // Jounal of Monetary Economics, Vol. 21, N3.

26. Romer C. (1999). Changes in Business Cycles: Evidence and Explanations // Journal of Economic Perspectives. Vol. 13, N2.

27. Rebelo S.(2005). Real Business Cycle Models: Present, Past and Future//Scandinavian

4. Journal of Economics, Vol. 107, N2.

28. McCandles G. (2008). The ABC's of RBC's: An Introduction to Dynamic Macroeconomic Models // Cambridge. MA London. England. Harvard University Pres. 


\section{ECONOMIC CRISIS THEORY OR ECONOMIC THEORY CRISIS?}

\section{ELGUJA MEKVABISHVILI}

https://doi.org/10.35945/gb.2018.06.002

Doctor of Economic Sciences, Professor

Ivane Javakhishvili Tbilisi State University,

Academician of the Academy of Economic Sciences of Georgia, Georgia

elguja.mekvabishvili@tsu.ge

\section{KEYWORDS: ECONOMIC CRISIS, GLOBAL FINANCIAL CRISIS, CRISIS "POINT OF FORECAST",}

"PREDICTION CORRIDOR", "STATIONARY MODES " OF THE FUNCTIONING OF THE ECONOMY

\section{SUMMARY}

The global financial crisis has brought a new impulse to the discussion of the problem of economic crisis. Economists have divided into two groups - one group believes the main reason for the crisis is the failure of economic theory. The second group thinks that economists have not been charged in the formation of economic crisis.

The most problematic aspect of the economic crisis is their prediction. Mainstream neoclassical economic theory completely excludes the possibility of predicting crises.
In the analysis of this issue, we use the concepts: "point prediction", "prediction corridor", "stationary regime" of economy functioning, and N. Kondratiev's Great Cycles Conjunction Theory.

There is possible to define the "prediction's corridors" within the stationary regimes of economy functioning. In these periods the economy is characterized with high quality of volatility. By observing the main economic indicators in these periods, we think, it is possible to predict the approximate date of the economic crisis. 